\title{
PENGEMBANGAN APLIKASI E-CATALOG AUGMENTED REALITY SEBAGAI MEDIA PEMASARAN PROPERTY
}

\author{
Muhammad Rizal, Muhammad Rusmin \\ Teknik Informatika STMIK AKBA ${ }^{1}$, Komputerisasi Akuntansi STMIK AKBA ${ }^{2}$ \\ Email: rizal@akba.ac.id ${ }^{1}$, rusmin@akba.ac.id ${ }^{2}$
}

\begin{abstract}
ABSTRAK
Bisnis property di Indonesia yang semakin meningkat dari tahun ke tahun. Dengan banyaknya pesaing di bisnis ini tentunya para pengusaha properti berusaha untuk menarik konsumen. Media promosi yang digunakan pengusaha masih menggunakan cara biasa yaitu promosi melalui brosur dan website media tersebut masih dirasa kurang efektif karena mempuyai view yang terbatas sehingga calon konsumen kesulitan membayangkan model rumah yang akan dibeli. Dengan munculnya teknologi augmented reality, maka pengusaha di bisnis peoperty mengadopsi teknologi ini dalam pemasaran produk property. Augmented Reality adalah teknologi yang menggabungkan dunia virtual dalam dunia nyata secara langsung. Teknologi ini mampu menampilkan objek 3D secara nyata, sehingga konsumen dapat melihat model property lebih nyata dan menarik. Metode yang digunakan pada penelitian ini adalah agile SDLC. Hasil penelitian ini adalah menghasilkan suatu aplikasi yang berjalan pada platform android sebagai salah satu penunjang dalam promosi pemasaran produk property.
\end{abstract}

Kata Kunci: property, pemasaran, augmented reality.

\begin{abstract}
The property business in Indonesia is increasing from year to year. With many competitors in this business, of course property entrepreneurs are trying to attract consumers. Promotional media used by entrepreneurs still use the usual method, namely promotion through brochures and media websites that are still considered ineffective because they have a limited view so that prospective customers have difficulty imagining the model of the house to be purchased. With the advent of augmented reality technology, entrepreneurs in the peoperty business adopted this technology in the marketing of property products. Augmented Reality is a technology that combines the virtual world in the real world directly. This technology is able to display $3 D$ objects in a real way, so that consumers can see property models more real and interesting. The method used in this study is Agile SDLC. The results of this research are to produce an application that runs on the Android platform as one of the supports in the promotion of property product marketing.
\end{abstract}

Keywords: property, marketing, augmented reality.

\section{Pendahuluan}

Bisnis properti saat memang sedang menjamur baik di kota-kota besar maupun kota-kota kecil. Hal ini dikarenakan kebutuhan masyarakat yang semakin tinggi untuk memiliki rumah sendiri. Selain itu, properti juga bisa menjadi investasi yang menjanjikan dikarenakan nilainya yang terus bertambah setiap tahun. Karena itulah sekarang muncul pebisnis properti baru, baik sebagai broker maupun biasanya 
hanya menggunakan brosur atau banner yang dalam bentuk 2D biasa menjadi lebih nyata, menarik perhatian dan berbeda. Hal ini dikarenakan ketika saat menggunakan Augmented Reality, objek 3D akan muncul di atas gambar marker 2D yang ada di brosur melalui aplikasi yang dipasang di perangkat Android [1].

Secara umum Augmented Reality bisa didefinisikan sebagai lingkungan nyata yang ditambahkan objek virtual. Penggabungan objek nyata dan virtual dimungkinkan dengan teknologi display yang sesuai, interaktivitas dimungkinkan melalui perangkat-perangkat input tertentu. Augmented Reality memungkinkan pengguna untuk melihat lingkungan nyata, dengan objek virtual yang ditambahkan atau tergabung dengan lingkungan nyata [2].

Dengan banyaknya kompetitor disektor bisnis property tentu diperlukan inovasi yang berbeda supaya produk yang dijual menjadi lebih menarik konsumen. Dalam aktifitas promosi produk propery terdapat beberapa cara pendekatan promosi yaitu (1) menggunakan media cetak brosur. (2) menggunakan media elektronik website.

Strategi pemasaran yang seperti itu masih kurang menarik minat konsumen. Oleh karena itu supaya promosi produk lebih menarik, nyata dan berbeda, maka digunakan teknologi augmented reality.

\section{Tinjauan Pustaka}

\subsection{Augmented Reality}

Augmented Reality merupakan upaya untuk menggabungkan dunia nyata dan dunia virtual yang dibuat melalui komputer sehingga batas antara keduanya menjadi sangat tipis.Chafied mengungkapkan dalam penelitiannya
"Augmented Reality atau yang biasa disebut dengan AR bukan merupakan teknologi baru.Teknologi ini telah ada selama hampir 40 tahun, setelah diperkenalkan aplikasi Virtual Reality (VR) untuk pertama kalinya. Pada saat itu, penelitian-penelitian teknologi yang dilakukan ditujukan untuk aspek hardware.

\subsection{Unity 3D}

Unity adalah sebuah game engine yang memungkinkan Anda, baik perseorangan maupun tim, untuk membuat sebuah game 3D dengan mudah dan cepat. Secara default, Unity telah diatur untuk pembuatan game bergenre First Person Shooting (FPS), namun Unity juga bisa digunakan untuk membuat game bergenre Role Palying Game (RPG) dan Real Time Strategy (RTS). Selain itu, Unity merupakan sebuah engine multiplatform yang memungkinkan game yang dibangun di-publish untuk berbagai platform seperti Windows, Mac, Android, IOS, PS3 dan Wii.

\subsection{Software Development Kit Vuforia}

Vuforia merupakan software untuk Augmented Reality yang dikembangkan oleh Qualcomm, yang menggunakan sumber yang konsisten mengenai computer vision yang fokus pada image recognition. Vuforia mempunyai banyak fitur-fitur dan kemampuan yang dapat membantu pengembang untuk mewujudkan pemikiran mereka tanpa adanya batas secara teknikal. Dengan support untuk iOS, Android dan Unity 3D, platform Vuforia mendukung para pengembang untuk membuat aplikasi yang dapat digunakan dihampir seluruh jenis smartphone dan tablet. Target pada vuforia 
merupakan objek pada dunia nyata yang dapat dideteksi oleh kamera, untuk menampilkan objek virtual

\section{Metode Penelitian}

Metode yang digunakan dalam penelitian ini adaalah menggunakan model pengembangan Agile SDLC seperti yang terlihat pada gambar 3.1

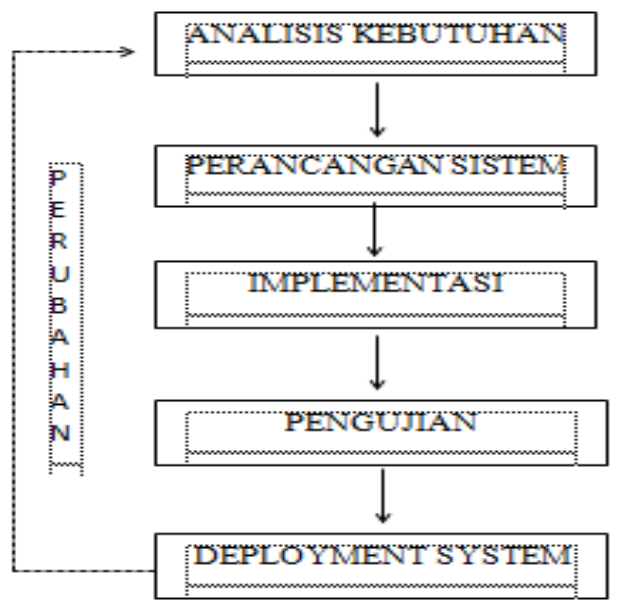

Gambar 3.1 Tahapan Penelitian

1. Tahap Analisis Kebutuhan

Tahapan analisis kebutuhan dilakukan untuk menentukan kebutuhan functional dan non functional aplikasi augmented reality yang akan dibangun.

2. Perancangan Sistem

Tahapan perancangan sistem dilakukan untuk perancangan penanda(marker) dan struktur menu aplikasi dengan tujuan memudahkan user dalam navigasi aplikasi

3. Implementasi

Tahapan implementasi adalah tahapan dimana aplikasi dibuat sesuai konsep awal perancangan. Implementasi koding menggunakan bahasa pemrograman $\mathrm{C} \#$ dengan engine Unity, library Vuforia SDK.

4. Pengujian Aplikasi

Pada tahap ini dilakukan pengujian aplikasi yang dibuat, tujuan utama pengujian yaitu untuk mengetahui apakah aplikasi yang dibuat sudah sesuai dengan yang diharapkan. Pengujian dilakukan menggunakan metode pengujian alfa, pengujian untuk membantu dalam mengungkap kesalahan pada aplikasi perangkat lunak sudah berjalan sesuai yang diharapkan.

5. Deployment System

Pada tahapan ini system siap digunakan oleh konsumen. Jika dalam deployment system terdapat kesalahan, maka akan dilakukan pengulangan kembali ketahap analisis untuk memperbaiki serta menambahkan kekurangan fungsi program.

\section{Hasil dan Pembahasan}

\subsection{Tampilan SplashScreen}

Aplikasi ARTalog Home Perumahan Azzam Residence Tampilan Splashscreen merupakan tampilan awal pada aplikasi ARTalog Home Perumahan Azzam Residence sebelum masuk pada menu utama aplikasi.

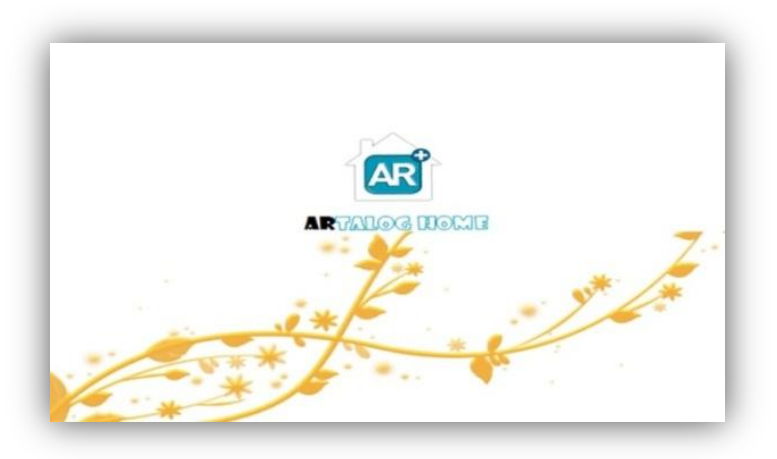

Gambar 4.1 Tampilan SplashScreen Aplikasi ARTalog Home 


\subsection{Tampilan Menu Utama Aplikasi}

Pada menu utama terdiri dari 7 tombol menu, yaitu tombol Menu Info ARTalog Home, Menu Info Perumahan, Menu Developer ARTalog Home, Menu Preview AR Object, Menu Tutorial/Home, Menu Preview Video Object dan Menu Exit. Setiap tombol menu memiliki fungsi masingmasing sesuai dengan konsep yang telah direncanakan.

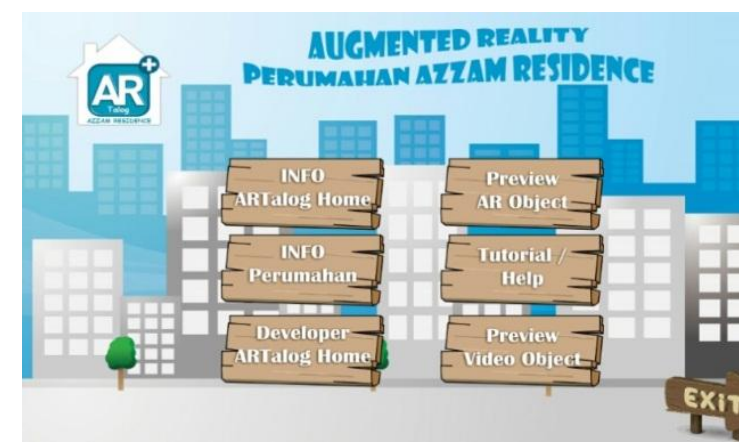

Gambar 4.2 Menu Utama Aplikasi

\subsection{Tampilan Menu Preview AR Object}

Pada AR Object ini terdapat 1 sub menu didalamnya, dimana sub menu tersebut masuk ke layar untuk menampilkan objek Rumah 3D.

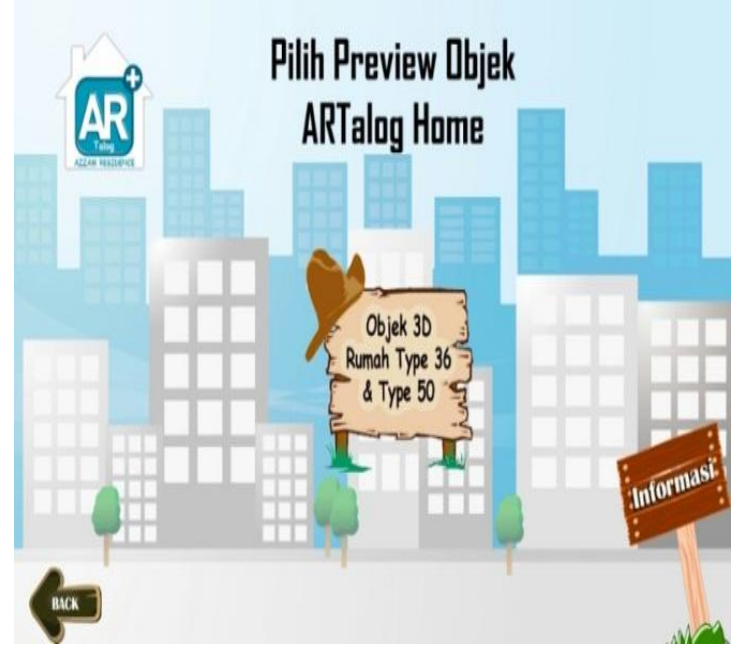

Gambar 4.3 Tampilan Menu Preview AR Object
4.4 Augmented Reality 3D Rumah Type 36 Pada sub Menu Augmented Reality 3D, jika user mengarahkan kamera ke gambar/marker pada brosur, objek bangunan 3D akan tampil diatas gambar tersebut.

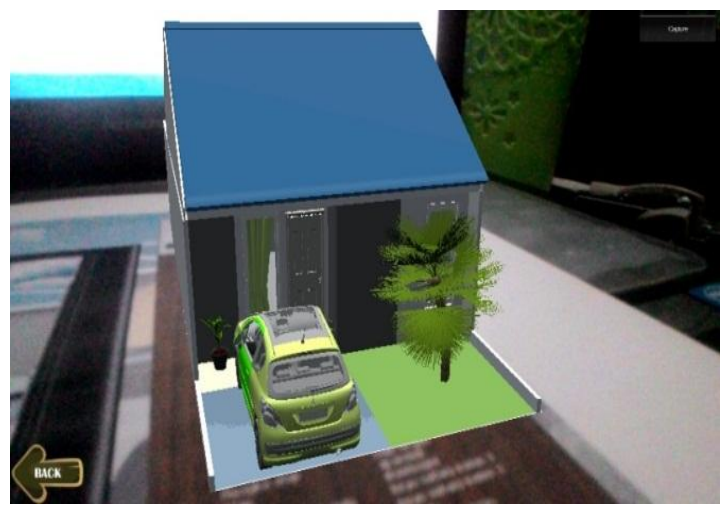

Gambar 4.4 Augmented Reality 3D Rumah Type 36

Pada Penelitian ini, dilakukan pengujian alfa untuk menguji fungsionalitas dari aplikasi yang dibuat. Pengujian alfa bertujuan untuk identifikasi dan menghilangkan error sebelum sampai ke end user. Pengujian alfa pada aplikasi ini dilakukan dengan menggunakan device android Pengujian ini dilakukan untuk mengetahui kinerja aplikasi.

Tabel 1 Pengujian jarak antara kamera dengan marker (jarak terdekat)

\begin{tabular}{|c|c|c|c|}
\hline $\begin{array}{c}\text { Kode } \\
\text { Uji }\end{array}$ & Marker & Jarak & Hasil \\
\hline $\begin{array}{c}\text { Xiaomi } \\
01\end{array}$ & $\begin{array}{c}\text { Denah } \\
\text { Type } 36\end{array}$ & $5 \mathrm{~cm}$ & $\begin{array}{c}\text { Marker } \\
\text { Berhasil } \\
\text { terdeteksi }\end{array}$ \\
\hline $\begin{array}{c}\text { Xiaomi } \\
03\end{array}$ & $\begin{array}{c}\text { Denah } \\
\text { Type } 50\end{array}$ & $5 \mathrm{~cm}$ & $\begin{array}{c}\text { Marker } \\
\text { Berhasil } \\
\text { terdeteksi }\end{array}$ \\
\hline $\begin{array}{c}\text { Xiaomi } \\
05\end{array}$ & $\begin{array}{c}\text { Video } \\
\text { Type } 36\end{array}$ & $5 \mathrm{~cm}$ & $\begin{array}{c}\text { Marker } \\
\text { Berhasil } \\
\text { terdeteksi }\end{array}$ \\
\hline $\begin{array}{c}\text { Xiaomi } \\
07\end{array}$ & $\begin{array}{c}\text { Video } \\
\text { Type } 50\end{array}$ & $5 \mathrm{~cm}$ & $\begin{array}{c}\text { Marker } \\
\text { Berhasil } \\
\text { terdeteksi }\end{array}$ \\
\hline
\end{tabular}


Tabel 2 Pengujian jarak antara kamera dengan marker (jarak terjauh)

\begin{tabular}{|c|c|c|c|}
\hline $\begin{array}{c}\text { Kode } \\
\text { Uji }\end{array}$ & Marker & Jarak & Hasil \\
\hline $\begin{array}{c}\text { Xiaomi } \\
01\end{array}$ & $\begin{array}{c}\text { Denah } \\
\text { Type } 36\end{array}$ & $20 \mathrm{~cm}$ & $\begin{array}{c}\text { Marker } \\
\text { Berhasil } \\
\text { terdeteksi }\end{array}$ \\
\hline $\begin{array}{c}\text { Xiaomi } \\
03\end{array}$ & $\begin{array}{c}\text { Denah } \\
\text { Type } 50\end{array}$ & $20 \mathrm{~cm}$ & $\begin{array}{c}\text { Marker } \\
\text { Berhasil } \\
\text { terdeteksi }\end{array}$ \\
\hline $\begin{array}{c}\text { Xiaomi } \\
05\end{array}$ & $\begin{array}{c}\text { Video } \\
\text { Type } 36\end{array}$ & $20 \mathrm{~cm}$ & $\begin{array}{c}\text { Marker } \\
\text { Berhasil } \\
\text { terdeteksi }\end{array}$ \\
\hline $\begin{array}{c}\text { Xiaomi } \\
07\end{array}$ & $\begin{array}{c}\text { Video } \\
\text { Type } 50\end{array}$ & $20 \mathrm{~cm}$ & $\begin{array}{c}\text { Marker } \\
\text { Berhasil } \\
\text { terdeteksi }\end{array}$ \\
\hline
\end{tabular}

\subsection{Hasil Pengujian Blackbox}

Berikut ini adalah hasil pengujian sistem berdasarkan hasil pengujian Blackbox :

Tabel 3 Tabel Hasil Pengujian Blackbox

\begin{tabular}{|c|c|c|c|c|c|c|c|c|c|c|c|}
\hline \multicolumn{12}{|c|}{ Hasil Penqujian Blackbox ARTalog Home } \\
\hline \multirow{2}{*}{ Butir Uji } & \multicolumn{10}{|c|}{ Responden } & \multirow{2}{*}{$\begin{array}{l}\text { Rata } \\
\text { Rata }\end{array}$} \\
\hline & 1 & 2 & 3 & 4 & 5 & 6 & 7 & 8 & 9 & 10 & \\
\hline Splash Screen & 4 & 5 & 5 & 4 & 5 & 4 & 4 & 4 & 4 & 4 & 4,3 \\
\hline $\begin{array}{c}\text { Info ARTalog } \\
\text { Home }\end{array}$ & 4 & 5 & 4 & 3 & 5 & 4 & 4 & 4 & 4 & 4 & 4,1 \\
\hline Info Perumahan & 5 & 5 & 5 & 5 & 5 & 4 & 4 & 4 & 4 & 4 & 4,5 \\
\hline $\begin{array}{c}\text { Developer } \\
\text { ARTalog Home }\end{array}$ & 4 & 4 & 4 & 4 & 4 & 4 & 4 & 4 & 4 & 5 & 4,1 \\
\hline $\begin{array}{c}\text { Preview AR } \\
\text { Object }\end{array}$ & 5 & 5 & 5 & 4 & 5 & 4 & 4 & 4 & 4 & 4 & 4,4 \\
\hline Tutorial/Help & 4 & 4 & 4 & 4 & 4 & 4 & 4 & 3 & 4 & 4 & 3,9 \\
\hline $\begin{array}{c}\text { Preview Video } \\
\text { Object }\end{array}$ & 5 & 5 & 5 & 4 & 5 & 4 & 4 & 4 & 4 & 4 & 4,4 \\
\hline Exit & 5 & 5 & 5 & 4 & 5 & 4 & 4 & 4 & 4 & 4 & 4,4 \\
\hline & & & & & & & & & & & 4,3 \\
\hline
\end{tabular}

Hasil Perhitungan aplikasi e-catalog augmented reality

Keterangan :

$\begin{array}{lll}\text { SB } & \text { : Sangat Baik } & =5 \\ \mathrm{~B} & \text { : Baik } & =4 \\ \mathrm{C} & \text { : Cukup } & =3 \\ \mathrm{~K} & \text { : Kurang } & =2 \\ \mathrm{KS} & \text { : Kurang Sekali } & =1\end{array}$

1) Menghitung Nilai Aspek :

Rata - Rata Nilai Aspek $=\frac{\text { Jumlah Nilai }}{\text { Jumlah Responden }}$

2) Menghitung Total Rata-Rata Nilai :

Total Rata - Rata Nilai $=\frac{\text { Total Penilaian }}{\text { Jumlah Aspek }}$

3) Hasil Presentasi Perhitungan

Hasil Presentasi $=\frac{\text { Total Rata }- \text { Rata Nilai }}{5} * 100 \%$

Tabel 3 diatas menunjukkan 8 aspek yang menjadi tolak ukur dalam pengujian aplikasi e-catalog augmented reality. Aspek pertama yaitu Splashscreen, aspek ini dengan Perolehan jumlah nilai dari responden sebesar 4,3, artinya aspek ini terpenuhi dengan baik. Aspek yang kedua yaitu Info e-catalog augmented reality, pada aspek ini memperoleh jumlah nilai dari responden sebesar 4,1, artinya aspek ini terpenuhi dengan baik. Aspek yang ketiga yaitu Info Perumahan, pada aspek ini memperoleh jumlah nilai dari responden sebesar 4,5, artinya aspek ini terpenuhi dengan baik. Aspek yang keempat yaitu Developer e-catalog augmented reality, pada aspek ini memperoleh jumlah nilai dari responden sebesar 4,1 artinya aspek ini terpenuhi cukup baik. Aspek yang kelima yaitu Preview AR Object, pada aspek ini memperoleh jumlah nilai dari responden sebesar 4,4, artinya aspek ini terpenuhi dengan baik. Aspek yang keenam yaitu Tutorial/Help, pada aspek ini memperoleh jumlah nilai dari responden sebesar 3,9, artinya aspek ini terpenuhi dengan baik. Aspek yang ketujuh yaitu Preview Video Object, pada aspek ini memperoleh jumlah nilai dari responden sebesar 4,4 artinya aspek ini terpenuhi dengan baik. Aspek yang kedelapan yaitu Exit, pada kriteria ini 
memperoleh jumlah nilai dari responden sebesar 4,4, artinya aspek ini terpenuhi dengan baik.

\section{Kesimpulan}

Berdasarkan pengembangan perangkat lunak yang telah dilakukan dari hasil pengujian, maka dapat disimpulkan bahwa semua aspek pengujian dalam aplikasi terpenuhi dengan baik dengan mendapatkan total nilai keseluruhan $86 \%$, dinyatakan layak dan secara fungsional sistem dapat menghasilkan output yang diharapkan. Sehingga Aplikasi e-catalog augmented reality layak diterapkan sebagai salah satu bentuk media promosi penjualan produk property.

\section{Daftar Pustaka}

[1] Ahmad Arif Faizin, Maman Somantri, and Yuli Christyono. Aplikasi Media Pemasaran Properti Dengan Menggunakan Teknologi Augmented Reality Pada Perangkat Android. Jurnal Transient.

[2] Fernando, Mario. 2013. Membuat Aplikasi Android Augmented Reality Menggunakan Vuforia SDK. Solo : Dhika Prihantono.

[3] R. Azuma, 1997 "A Survey of Augmented Reality", Teleoperators and Virtual Environments.

[4] Suryana, R. A. 2012, "Pengembangan Media Brosur Berbasis Augmented Reality pada Pembuatan Gedung Fakultas Virtual Universitas Pendidikan Indonesia dalam Bentuk Objek 3D" Jurnal Ilmu Komputer Universitas Pendidikan Indonesia. 